\title{
Educadoras da infância pesquisando e refletindo sobre a própria prática em matemática* $^{*}$
}

\section{Kindergarten and pre-school educators researching and reflecting about their own practice in mathematics}

\author{
Regina Célia Grando** \\ Adair Mendes Nacarato***
}

\section{RESUMO}

A presente pesquisa - realizada com um grupo de 23 professoras da Educação Infantil, inseridas num projeto de formação continuada no ambiente da universidade - teve como questão de investigação "Que dinâmicas vivenciadas em um grupo de formação de educadoras da infância possibilitaram a aprendizagem profissional em matemática?" E, como objetivos: (1) identificar quais tipos de leituras teóricas e quais dinâmicas de trabalho de articulação teoria e prática produzem significados para e reflexões sobre a prática docente; (2) analisar os contextos de formação nos quais o professor passa a assumir um papel de investigador de sua própria prática. Trata-se de uma pesquisa de abordagem qualitativa cuja documentação foi constituída de: questionário inicial (perfil dos sujeitos); registros reflexivos sobre o papel do jogo e sobre as dinâmicas vivenciadas no grupo de formação; trabalho de investigação realizado em sala de aula. Dentre as dinâmicas que revelaram indícios de aprendizagem profissional, destacamos: (I) o registro da criança possibilitando uma investigação da própria prática; (II) as leituras teóricas produzindo sentidos à prática docente; (III) o

* Este trabalho foi desenvolvido na linha de pesquisa Matemática, cultura e práticas pedagógicas e contou com a colaboração de Luana Toricelli, bolsista Probaic/USF.

** Doutora em Educação, Docente do Programa de Pós-Graduação Stricto Sensu em Educação da Universidade São Francisco (USF).

*** Doutora em Educação, Docente do Programa de Pós-Graduação Stricto Sensu em Educação da Universidade São Francisco (USF). 
GRANDO, R. C.; NACARATO, A. M. Educadoras da infância pesquisando e refletindo sobre a própria prática em matemática

jogo e a brincadeira infantil possibilitando um redimensionamento curricular da matemática na Educação Infantil; (IV) a apropriação e (re)significação pelas professoras da dinâmica de "dar a voz".

Palavras-chave: investigação da própria prática; jogos e brincadeiras; registro.

\begin{abstract}
This research was carried out by a group of 23 kindergarten and pre-school teachers involved in a project on continuous formation in an academic environment. Their question for investigation was: which dynamics experienced by a group of undergraduate kindergarten and pre-school teachers allowed the professional learning of mathematics? The aims of the research were (1) to identify the types of theoretical interpretations and working dynamics for the integration of theory and practice that produce meanings for the reflections on the teaching practice, and (2) to analyze the formation contexts in which the teacher becomes an investigator of his/her own practice. It is a qualitative approach whose documentation includes a starting questionnaire (personal characteristics), reflective registers on the importance of games and the dynamics experienced by the formation group, and an investigation work developed in classrooms. Among all the dynamics that revealed signs of professional learning, we point out at (I) the child's register, which makes it possible to have an investigation of his/her own practice; (II) the theoretical interpretations that give the teaching practice sense; (III) the kindergarten games and plays allowing a curricular dimension for mathematics in kindergarten; and (IV) the appropriation and (re)signification of "letting speak" by the teachers who worked with the dynamics.

Key-words: investigating one's own practice; games and plays; register.
\end{abstract}

\title{
Introdução
}

O presente estudo foi realizado com um grupo de professoras que atuam na Educação Infantil ${ }^{1}$ da rede municipal de Itatiba/SP e alunas do curso de Pedagogia da USF. Esse grupo foi constituído em agosto/2004 com o objetivo de discutir o ensino de matemática nesse nível de escolarização. O grupo era composto, inicialmente, por 27 participantes, com tempo de magistério diversificado, variando de 4 a 24 anos de

${ }^{1}$ As docentes atuam na faixa de escolarização dos 4 aos 6 anos de idade. 
docência, todas residentes em Itatiba, 23 da rede de ensino do município de Itatiba, 1 representante da Secretaria de Educação e 3 alunas da graduação.

Considerando que foi acordado com a Secretaria Municipal de Educação que a participação dos professores seria voluntária, mas haveria a expedição de um certificado de 30 horas, como curso de extensão, prevíamos que a emissão de certificado atrairia ao curso professoras que não estariam preocupadas com a sua formação e desenvolvimento profissional, mas apenas interessadas em mais um certificado para acesso à carreira docente. Tínhamos, dessa forma, um desafio pela frente: provocar mudanças nesse tipo de concepção e cativar essas professoras para a importância do trabalho coletivo, das discussões teóricas, das práticas reflexivas e investigativas. Ao longo do semestre, quatro dessas participantes deixaram o curso, que encerrou o semestre com um grupo de 23 participantes, das quais a maioria permaneceu em 2005.

Estabelecemos com as professoras que esse espaço de formação constituiria, para nós, cenário para nossas pesquisas acadêmicas e que haveria uma carga horária do curso destinada à realização de uma atividade investigativa em sala de aula, com os próprios alunos.

Dada a diversidade de temas para o ensino de matemática nessa faixa etária e por ter a maioria das participantes apontado o jogo como a principal atividade na qual trabalham a matemática na Educação Infantil, elegemos como foco dos encontros desse semestre os jogos e brincadeiras infantis, com destaque para o papel do registro.

A dinâmica dos encontros tinha como ponto de partida leituras de textos - distribuídos previamente - e discussões sobre temas relativos à matemática na Educação Infantil, promovendo o confronto teoria/prática, para tentar inserir a professora num processo reflexivo de sua prática pedagógica. Dessa forma, em cada encontro aconteceram momentos de discussão/reflexão teórica e de produção/análise de materiais para a sala de aula da Educação Infantil. As professoras participantes puderam: produzir, aplicar e analisar atividades; analisar os registros produzidos pelos alunos e elaborar reflexões que foram socializadas no grupo de formação, tendo como suporte os textos teóricos lidos. Toda essa dinâmica foi documentada e se constitui no nosso material para análise.

Ao final do semestre, dispúnhamos da seguinte documentação: questionário inicial (perfil dos sujeitos); registros reflexivos sobre o papel do jogo e sobre as dinâmicas vivenciadas no grupo de formação (registros escritos); diários de campo das pesquisadoras; trabalho de investigação realizado em sala de aula (texto escrito, acompanhado dos registros dos alunos) e avaliação final do processo vivenciado (texto escrito e avaliação oral, gravada em áudio e transcrita). 
GRANDO, R. C.; NACARATO, A. M. Educadoras da infância pesquisando e refletindo sobre a própria prática em matemática

Elegemos a seguinte questão de investigação para este estudo: Que dinâmicas vivenciadas em um grupo de formação de educadoras da infância possibilitaram a aprendizagem profissional em matemática?

Os objetivos para o estudo são: (1) identificar quais tipos de leituras teóricas e dinâmicas de trabalho de articulação teoria e prática produzem significados para reflexões sobre a prática docente; (2) analisar os contextos de formação nos quais o professor passa a assumir um papel de investigador de sua própria prática.

Dentre as dinâmicas que revelaram indícios de aprendizagem profissional, destacamos: (I) o registro da criança possibilitando uma investigação da própria prática; (II) as leituras teóricas produzindo sentidos à prática docente; (III) o jogo e a brincadeira infantil possibilitando um redimensionamento curricular da matemática na Educação Infantil; (IV) a apropriação e (re)significação, pelas professoras, da dinâmica de "dar a voz". O fato de as distinguirmos para efeito de análise não significa que sejam excludentes. ${ }^{2}$

\section{$O$ registro da criança possibilitando uma investigação da própria prática}

No trabalho desenvolvido no grupo de formação de educadoras da infância, procuramos contemplar as múltiplas formas de expressão e as diferentes linguagens - oral, pictórica, corporal e textual - que caracterizam o trabalho das crianças na Educação Infantil. O registro nessas diferentes linguagens foi valorizado como instrumento de reflexão e avaliação para o professor e, para os alunos, como estratégia de comunicação de idéia e de reflexão sobre a atividade desenvolvida.

Smole et al. (2000) apontam o registro oral como o mais natural na Educação Infantil, visto que a maioria das crianças, ao ingressar na escola, registra o que pensou ou fez por meio da oralidade. Esse tipo de registro, embora seja o mais adequado - comunicação simples, ágil e direta - e possibilite ao aluno conectar a sua linguagem e seu conhecimento com o grupo social em que está inserido, não propicia o registro da memória do pensamento desencadeado, para posterior reflexão e mediação pelo professor.

${ }^{2}$ Neste texto, os documentos utilizados para o recorte das falas ou depoimentos das professoras serão identificados com as seguintes siglas: q.i. (questionário inicial); r.r. (registro reflexivo); t.i. (trabalho de investigação); d.c. (diário de campo das pesquisadoras); e a.f. (avaliação final do processo vivenciado). 
O registro pictórico, por desenhos, como uma primeira linguagem gráfica serve não apenas para documentar as vivências, registrar experiências, sensações, mas também para expressar o que foi mais significativo para a criança naquela atividade desenvolvida. A socialização dos vários desenhos permite às crianças ampliar os diferentes pontos de vista e os aspectos vivenciados que foram por elas ressaltados. Para o professor, analisar a evolução dos registros pictóricos das crianças possibilita acompanhar o desenvolvimento de conceitos matemáticos, tais como o controle na variação de quantidades, as representações simbólicas, a exploração do espaço e a proporcionalidade. Segundo Smole et al. (2000, p. 25), "as representações pictóricas realmente evoluem se os alunos tiverem chance de brincar muitas vezes, conversar sobre a brincadeira e sobre seus próprios registros".

O registro textual, também valorizado pelas autoras, pode ser realizado coletivamente pelo professor - o escriba - e as crianças, que ainda não escrevem, mas reconhecem nesse tipo de registro uma forma de expressão e comunicação de idéias. $\mathrm{O}$ texto coletivo pode ser retomado em vários momentos, como forma de registro da memória; como garantia de que, no caso do registro de regras de jogos e brincadeiras, as regras sejam cumpridas; ou, mesmo, para a reescrita.

As educadoras, de uma maneira geral, revelaram, inicialmente, ter prática com o registro das atividades realizadas com as crianças por meio de desenhos (pictórica) - pelas crianças - e/ou por meio de relatórios elaborados por elas. Dessa forma, em situações de jogos e brincadeiras, práticas comuns na Educação Infantil, as professoras costumavam solicitar que as crianças desenhassem a brincadeira realizada, mas sem preocupação em analisar a evolução dos registros, ou mesmo a compreensão dos aspectos matemáticos nele presentes. $\mathrm{O}$ interesse restringia-se à memória da atividade. Esse fato se evidencia pela fala:

Eu, particularmente, sempre incluí, em meu planejamento semanal, atividades de matemática, as minhas recreações sempre foram feitas com jogos, tinha o costume de registrar com as crianças, mas este curso deu oportunidade de ver e vivenciar a "riqueza" que é fazer os registros de diversas maneiras, o "retomar o jogo" eu não via dessa maneira que agora vejo e valorizo. (VC, a.f.) ${ }^{3}$

3 Para identificação das educadoras, utilizaremos as iniciais dos nomes. 
GRANDO, R. C.; NACARATO, A. M. Educadoras da infância pesquisando e refletindo sobre a própria prática em matemática

As atividades desenvolvidas no grupo, que contemplaram a realização de brincadeiras e jogos com as professoras, a elaboração de registros por elas, o acompanhamento da evolução dos registros realizados por crianças em um vídeo comercial apresentado 4 e posterior aplicação na sala de aula, com análise dos registros das próprias crianças, possibilitaram a reflexão, por parte das professoras, quanto aos diferentes papéis atribuídos aos registros, como afirma a professora:

Outro fator marcante foi a questão do registro e de sua importância, tanto para o professor para o qual este serve como um diagnóstico mostrando possíveis caminhos a serem seguidos, quanto para as crianças, já que representa o momento de tomada de consciência para elas. (IA, a.f.)

As educadoras, ao analisarem os registros - produzidos pelas crianças durante a mesma atividade que haviam desenvolvido (e registrado) -, puderam reconhecer o seu valor pedagógico, que pode ser evidenciado pela fala:

Achei importante ter conhecido melhor o significado do registro, tanto feito pelos alunos como do próprio professor, tudo isso me fez refletir sobre a minha prática. (AM, a.f.)

Essa prática de analisar o registro de alunos, avaliar sua evolução e anotar suas observações revela indícios de investigações do professor sobre a própria prática.

Ponte (2002), ao apontar duas condições necessárias para a atitude de investigação, a qual caracteriza como uma predisposição do professor para examinar a sua própria prática de forma crítica e sistemática, destaca: (1) a disposição deste para questionar, o que remete para o campo afetivo e para o campo das atitudes e (2) a necessidade do domínio, por parte do docente, de diversos instrumentos metodológicos. Com base em Alarcão (apud PonTe, 2002, p. 15), conclui: "a investigação não é algo que se possa realizar de forma rotineira, sem paixão, sem um verdadeiro envolvimento intelectual e afetivo".

4 SMOLE, Kátia S.; DINIZ, Maria Ignez; CÂNDIDO, Patrícia. Brincadeiras nas aulas de matemática (vídeo). São Paulo: Mathema, 2001. 
Percebemos, durante as atividades do grupo de formação, esse envolvimento das educadoras, refletindo sobre a sua própria vivência nas atividades lúdicas e de registro, e certa "curiosidade" e predisposição afetiva em realizar as mesmas atividades e análises com seus alunos. Ao mesmo tempo, os subsídios teóricos e metodológicos para a prática de investigação em sala de aula foram sendo construídos e discutidos coletivamente no grupo, por meio do acompanhamento da investigação realizada no vídeo comercial, dos ensaios de pequenas investigações realizadas em sala de aula por algumas professoras mais motivadas e da análise e discussão coletiva da aula de uma das professoras, gravada em vídeo. Destacamos uma fala que evidencia o que representaram essas atividades de reflexão no grupo:

Fazer este curso [participar do grupo de formação] me trouxe muita riqueza, pois proporcionou adquirir teoria vinculada à prática. Pude trocar experiências com os colegas, refletir e educar o "olhar" para as brincadeiras, para as interações e questionamentos e, principalmente, para o registro e sua importância. (FC, a.f.)

O trabalho final proposto ao grupo de formação foi a realização - cada professora em sua sala de aula - de uma seqüência de atividades, com registro, análise e apresentação oral e escrita para o grupo. Em todos os trabalhos foram priorizados os registros dos alunos como material de análise por parte das professoras. Notamos o quanto a análise de tais registros possibilitou a reflexão do professor com relação à sua própria prática. $\mathrm{O}$ depoimento a seguir evidencia tal fato:

Após a brincadeira [amarelinha] pedi que fizessem o registro dela e socializamos os registros durante a roda [discussão coletiva]. [...] Realizamos a brincadeira por algumas semanas consecutivas, sempre conversando sobre como foi a brincadeira. Então, pedi novamente que fizessem o registro da mesma atividade por meio do desenho. As crianças começaram a acrescentar elementos, desenhando as crianças na brincadeira, além de representar a jogada, desenhando a pedrinha na casa. Acredito que, se tivesse realizado também o registro durante todas as semanas em que brincaram, este poderia ter evoluído mais. Percebo que esta foi uma falha minha, já que é pelo registro que a criança tem a tomada de consciência. (IA, t.i.) 
GRANDO, R. C.; NACARATO, A. M. Educadoras da infância pesquisando e refletindo sobre a própria prática em matemática

Fica evidente, por essa fala, o grande significado da teoria para a prática do professor. O que lhe fornece indícios de que, se tivesse feito diferente, o resultado seria melhor? Provavelmente as discussões processadas no grupo, as experiências vivenciadas e a própria teoria consultada.

Esse fato pôde ser percebido em outros trabalhos em que as professoras propuseram às crianças o registro dos jogos e das brincadeiras, com os mais variados objetivos: a fim de resgatar a memória de como se joga, para registrar como o jogo parou, para comunicar aos colegas como se brinca, para identificar possíveis "erros", etc. Isso evidencia a apropriação, pelo professor, das múltiplas funções do registro e de seu papel na aprendizagem do aluno.

Em um dos trabalhos que destacamos, a professora analisou a evolução do registro de uma brincadeira realizada pelos seus alunos. Nas suas considerações finais, destacou, nas atitudes das crianças, aspectos que - segundo seu entendimento - só puderam ser observados a partir dos subsídios teóricos e das discussões processadas no grupo. Amplia a sua compreensão da importância do registro dos alunos e traz uma nova dimensão quanto ao registro, feito pelo professor, de sua própria prática. Destacamos o texto da professora que, mesmo longo, optamos por apresentar na íntegra, em razão de sua riqueza:

Quanto maior o hábito do professor de registrar sua prática, melhor será seu crescimento profissional. Mais importante ainda é o professor ter ciência do valor de seus registros, o quanto eles têm de informações valiosas não só para si mesmo, mas para quaisquer estudos. É necessário que os professores percebam sua capacidade de serem também pesquisadores, pois esta competência não pode estar apenas reservada para o nível acadêmico. A grande vantagem de o professor ser também pesquisador reside exatamente no fato de que este tem a sua disposição uma gama de recursos, que é a sua própria sala de aula, ou seja, ele pode facilmente aliar a teoria que aprende no nível acadêmico à sua prática cotidiana, o que só virá a melhorá-la, e neste sentido, o registro que faz de sua prática torna-se um valioso instrumento cientifico, uma vez que o cotidiano de sala de aula está distante da realidade acadêmica. Desta forma, é preciso mudar o paradigma e passar a ver o professor da educação básica como aliado na pesquisa científica. (VC, t.i., grifo nosso)

A fala dessa professora aproxima-se das concepções apontadas por Ponte (2002, p. 13), que, ao referir-se às potencialidades da investigação do professor sobre a sua própria prática, ressalta que: 
[além de] constituir uma condição necessária a uma prática profissional de qualidade [...], esta investigação pode contribuir fortemente para o desenvolvimento profissional dos professores implicados e o desenvolvimento organizacional das respectivas instituições, bem como gerar importante conhecimento sobre os processos educativos, útil para outros professores, para os educadores acadêmicos e para a comunidade em geral. É um fato incontornável que os professores estão em situação privilegiada para fornecer uma visão de dentro da escola sobre as suas realidades e problemas.

Notamos, assim, pelas situações destacadas, que tanto o registro do aluno, analisado pela professora, quanto o registro da professora possibilitaram momentos de reflexão sobre a sua prática e uma postura investigativa por parte da maioria das educadoras.

\section{As leituras teóricas produzindo sentidos à prática docente}

A relação teoria-prática vem se constituindo em uma preocupação constante nos programas de formação de professores. Provavelmente tal preocupação se tenha acentuado a partir das discussões sobre os saberes da experiência do professor e as tentativas de se estabelecer uma epistemologia da prática. Em muitos estudos, acabou prevalecendo uma dicotomia entre essas duas dimensões, com uma supervalorização da dimensão prática, desconsiderando-se o papel da teoria, numa perspectiva bastante pragmatista. Pimenta (2002) analisa a forma como as reformas curriculares do final da década de 1990 apropriaram-se do conceito de professor reflexivo, principalmente, distanciando-se, na maioria das vezes, das concepções subjacentes. Em alguns casos, como destaca a autora, vem ocorrendo "um oferecimento de treinamento para que o professor se torne reflexivo" (p. 23).

Outro conceito bastante banalizado tem sido o de professor investigador. Tornar o professor investigador e reflexivo de sua prática vem sendo, em alguns contextos de formação docente, considerado como a solução para muitos dos problemas enfrentados pela educação. E, na maioria dos casos, tais conceitos vêm sendo utilizados de forma bastante tecnicista. Sem dúvida, trata-se de uma forma reducionista de entendimento. Tanto os processos investigativos quanto os reflexivos do professor sobre sua própria prática não podem prescindir do 
GRANDO, R. C.; NACARATO, A. M. Educadoras da infância pesquisando e refletindo sobre a própria prática em matemática

papel da teoria. "O professor pode produzir conhecimento a partir da prática, desde que na investigação reflita intencionalmente sobre ela, problematizando os resultados obtidos com o suporte da teoria. E, portanto, como pesquisador de sua própria prática" (PimentA, 2002, p. 43).

Partindo, então, do pressuposto de que a teoria é fundamental na formação do professor, a questão que se coloca é: como promover esse movimento de "mão dupla" entre essas duas dimensões? De que forma a teoria deve ser trabalhada em programas de formação continuada? Quais dinâmicas devem ser estabelecidas para que o professor consiga perceber esse movimento?

Essas questões constituíam nossa preocupação no início do trabalho com as educadoras da infância. Experiências anteriores, como a de Nacarato (2000), por exemplo, já destacavam que promover leituras teóricas com professores não é suficiente para processos de mudanças na prática docente. Fiorentini, Nacarato e Pinto (1999, p. 56) argumentam que não é qualquer leitura que produz sentidos ao professor em exercício, mas aquelas que permitem ao professor articular as idéias do texto com suas experiências.

Larrosa (2002), ao abordar a questão formativa da leitura, afirma que esta deve ser pensada como "algo que nos forma (ou nos de-forma e nos trans-forma), como algo que nos constitui ou nos põe em questão naquilo que somos" (p. 133); deve ser pensada "como uma relação de produção de sentido" (p. 147). Para o autor, a produção de sentido está relacionada à experiência, por ele entendida como aquilo que nos passa, nos transforma. Como o próprio autor afirma, "o importante não é o texto senão a relação com o texto" (p. 137) e, nesse sentido, "a atividade de leitura é às vezes experiência e às vezes não" (p. 146).

Em se tratando de processos de formação, a escolha não apenas dos textos, mas também das dinâmicas para a sua discussão, é fundamental. A leitura do texto deve ser uma atividade que se revele em experiência, que possibilite a produção de sentidos pelo professor.

Dessa forma, tivemos o cuidado de selecionar textos que não apenas possibilitassem às professoras identificar-se com os contextos neles apresentados, mas também fossem disparadores de processos reflexivos. Além disso, adotamos, para sua discussão, dinâmicas que proporcionassem, no grupo, situações que exigiam que fossem narrados e discutidos elementos da prática e, também, que se refletisse sobre eles.

$\mathrm{O}$ texto era disponibilizado num encontro, para ser discutido em outro posterior, o que garantia um espaço de quinze dias para a leitura. No encontro seguinte, desenvolvia-se uma atividade prática, planejada com antecedência, de forma a possibilitar momentos de discussão e reflexão sobre ela, a partir da 
abordagem teórica do texto. O grupo envolvia-se em jogos e brincadeiras - em espaço aberto (no caso, utilizamos a quadra de esportes da universidade), ou na sala de aula (como o jogo do boliche, por exemplo, ou jogos de tabuleiro); apresentação de um vídeo comercial; apresentação de um vídeo da aula de uma das professoras do grupo; além de discussões em pequenos grupos, com relatos e trocas de experiências entre as professoras.

Essa dinâmica, que envolveu um movimento de "leitura - atividade prática - reflexão" a partir do texto, foi, no nosso entendimento, fundamental para que:

1) Ocorressem mudanças na própria concepção do papel desse espaço de formação, que se constituiu em um contexto de aprendizagem coletiva e que, de certa forma, se contrapôs às expectativas iniciais de algumas educadoras que buscavam atividades práticas para a sala de aula, conforme destacado no depoimento:

Quando iniciei este curso, meu principal objetivo era conhecer atividades e jogos para enriquecer minha prática em sala de aula. Agora, ao término do curso, percebo a importância da reflexão que fizemos, do suporte teórico, das leituras aliadas à prática. (AC, a.f.)

2) Houvesse a produção de sentidos das práticas das professoras, conforme o depoimento:

No decorrer do projeto, fui me envolvendo mais e percebendo que as atividades estão dentro de minha experiência, capacidade e criatividade. O que me falta é a teoria, a segmentação e finalização mais consistente delas. A teoria adquirida, de maneira extremamente prazerosa e prática nesses encontros, me proporcionou a segurança nas intervenções com as crianças, promovendo um avanço significativo e visível para ambas as partes. (CR, a.f.)

3) Surgissem momentos de tomada de consciência sobre as práticas desenvolvidas: 
GRANDO, R. C.; NACARATO, A. M. Educadoras da infância pesquisando e refletindo sobre a própria prática em matemática

Aprendendo a teoria na prática pude perceber quantas coisas passavam despercebidas nas atividades que realizamos na sala de aula, procurando, a partir de então, explorá-las ao máximo possível, enriquecendo a prática pedagógica. (IA, a.f.)

À medida que a teoria foi assumindo significado para a prática de sala de aula das professoras, o comprometimento destas com as leituras prévias foi se acentuando a ponto de, nos últimos encontros, muitas delas, espontaneamente, aplicarem e analisarem atividades suscitadas pelas leituras teóricas e trazerem suas análises para posterior discussão no grupo.

Essas dinâmicas acabaram suscitando em algumas educadoras novas concepções da própria educação infantil - como será discutido posteriormente - , destacadas por uma professora:

Por meio de estudos que fundamentaram toda uma prática e atividades em grupo, desenvolvemos maneiras diferentes de ver o mundo, os alunos, a escola e sua organização, enxergando a escola como um lugar, um espaço de manifestação da vida com toda sua complexidade de relações. Nesses encontros, nossos conhecimentos prévios e comuns foram transformados em conhecimentos acadêmicos. (ME, a.f.)

Conforme foi destacado na análise do item anterior, essas dinâmicas também desencadearam posturas investigativas em algumas educadoras. Em um dos encontros, uma delas deu o seguinte depoimento:

Sempre questionei os alunos para confrontar suas respostas com aquelas que constam das teorias; hoje, questiono o meu aluno, pois sei que posso teorizar a partir de seus argumentos. (CA, d.c.)

É o professor passando de consumidor a produtor de saberes e de teorias.

No processo de formação, não há como desconsiderar o papel que o grupo teve na aprendizagem dessas educadoras: 
Acho que, no início, o grupo deixava um pouco a desejar nas discussões, (até pelas novidades!), problema que foi superado nos encontros seguintes, quando começamos a expor nossas experiências pessoais, nossas dificuldades, nossas ansiedades. (DF, a.f.)

No contexto de formação, aqui analisado, a teoria - apresentada em forma de textos acadêmicos - não só possibilitou o processo reflexivo, como desencadeou momentos de investigação sobre a própria prática. No entanto, entendemos que a riqueza desses momentos foi propiciada pelo ambiente de respeito e colaboração do grupo, cujos participantes sempre se mostraram predispostos a: ouvir o colega, não ter medo de se expor, apresentar narrativas orais das atividades desenvolvidas e trazer suas pequenas investigações realizadas em sala de aula, principalmente com o registro das crianças.

Nesse sentido, podemos dizer que o grupo se constituiu numa comunidade de investigação e aprendizagem sobre a educação da infância, aproximandose das concepções defendidas por Cochran-Smith e Lytle (1999). Para essas autoras, em comunidades nas quais a investigação é uma postura, grupos de professores e licenciandos se envolvem em construção coletiva de conhecimento por meio de conversas e outras formas de análise e interpretação colaborativas. Conversas e produções escritas tornam seus conhecimentos tácitos mais visíveis, levantam questões e suposições sobre práticas comuns e geram dados que possibilitam novas ações na prática docente.

\section{$O$ jogo e a brincadeira infantil possibilitando um redimensionamento curricular da matemática na Educação Infantil}

Ao elegermos os jogos e as brincadeiras como foco no grupo de formação, entendemos serem essas as principais atividades na Educação Infantil. Como as próprias educadoras apontaram no questionário inicial de levantamento das expectativas do "curso", o trabalho com a matemática na Educação Infantil é usualmente desenvolvido em atividades com jogos (dominó; memória; boliche; quebra-cabeça) e brincadeiras (faz-de-conta; amarelinha; pular corda; caixa surpresa), em que ocorre a discussão, na maioria das vezes individualizada, entre a professora e o aluno. 
GRANDO, R. C.; NACARATO, A. M. Educadoras da infância pesquisando e refletindo sobre a própria prática em matemática

Inicialmente foram realizadas atividades corporais, na quadra de esportes, com brincadeiras e jogos cooperativos. A cada bloco de brincadeiras eram discutidos aspectos quanto ao desenvolvimento infantil, à exploração de conteúdos matemáticos nas brincadeiras, à resolução de problemas coletivamente e à metodologia de trabalho com jogos na Educação Infantil.

Durante a realização das atividades lúdicas, as professoras puderam vivenciar a prática com jogos e brincadeiras e refletir sobre ela. Algumas delas revelaram que não tinham consciência das várias potencialidades presentes nas atividades e do quanto estas poderiam ser exploradas interdisciplinarmente. Os conteúdos dos jogos e brincadeiras envolviam aspectos sociais, cognitivos, motores, afetivos e morais. Optamos por abordar os diferentes conteúdos de forma integrada, "de corpo inteiro" (FreIRE, 1997, p. 14). Para esse autor, corpo e mente devem ser considerados como um todo integrado e devem ter seu espaço na escola, principalmente na Educação Infantil. Dessa forma,

Fica difícil falar de Educação concreta na escola quando o corpo é considerado um intruso. A concretude do ensino depende, a meu ver, de ações práticas que dêem significado ao "dois mais dois" [...]. Sem viver concretamente, corporalmente, as relações espaciais e temporais de que a cultura infantil é repleta, fica difícil falar em educação concreta, em conhecimento significativo, em formação para autonomia, em democracia (FreIre, 1997, p. 14).

Nessa perspectiva, o currículo da Educação Infantil assume um caráter interdisciplinar, no sentido abordado por Pires (2000, p. 79), em que se estabelecem relações dinâmicas entre as diferentes disciplinas e os problemas da sociedade, representando uma comunicação entre os domínios do saber, uma "fecundação mútua" (FAZENDA, apud PirEs, 2000, p. 75).

Essa perspectiva curricular interdisciplinar foi explorada por várias educadoras nos trabalhos finais. Em um deles, a professora $\mathrm{CG}$ - em um processo que durou várias semanas - , após a realização da brincadeira de pega-pega com as crianças, produziu com elas um livro coletivo, contendo (1) dois textos produzidos coletivamente sobre as regras do jogo e sobre as atividades ocorridas e (2) os registros pictóricos da brincadeira, eleitos pelas crianças, após socialização, como os mais representativos da brincadeira realizada. A análise da atividade pela professora evidenciou a articulação na abordagem dos conteúdos matemáticos com os conteúdos da língua materna e as diferentes formas de expressão: corporal, pictórica e simbólica. 
Após a realização das atividades corporais com jogos e brincadeiras, optamos por apresentar um vídeo comercial que mostrava situações de intervenção pedagógica em salas de aula da Educação Infantil, com o objetivo de aproximar as discussões teóricas sobre o jogar e o brincar das atividades realizadas pelo próprio professor. A partir das imagens do vídeo e das discussões sobre a metodologia de trabalho com jogos e brincadeiras nas aulas de matemática, pudemos refletir sobre a importância da análise, pelo professor, da evolução dos registros das crianças; sobre a socialização das estratégias de jogo; e sobre a elaboração de textos coletivos contendo as regras.

Percebemos, naquele momento, a necessidade de aproximar ainda mais o trabalho da prática do professor daquele grupo, mais especificamente, da rede municipal de Itatiba/SP. Lançamos o desafio para os participantes: gostariam de desenvolver uma atividade, com jogos ou brincadeiras, que fosse registrada em vídeo e analisada pelo grupo? A professora CG aceitou o desafio e disponibilizou a sua sala de aula para a realização da atividade.

A atividade desenvolvida foi levada para o grupo, o que possibilitou a análise de seus limites e potencialidades. O relato da professora CG, acompanhado do registro videográfico, possibilitou uma reflexão coletiva sobre a intervenção realizada e motivou as outras participantes a experimentar atividades desse tipo, ou seja, atividades de investigação. $\mathrm{O}$ depoimento da professora CG revela como esse movimento de preparação, registro e análise coletiva da sua aula propiciou a reflexão sobre a sua própria prática:

Agora é um novo olhar sobre a teoria que a gente já viu em outras situações, o meu olhar com a teoria, é isso que eu notei, o meu olhar para aquilo que eu estou estudando é outro. Tá sendo legal, porque é aquela coisa, hoje eu sou professora pesquisadora, um tempo atrás eu incorporava uma prática dos cursos, e que faltava só confirmar se tal coisa acontecia realmente do jeito que estava escrito no livro. Eu lia o texto e observava, questionava para confirmar aquilo que eu li. Aqui eu tô percebendo que eu posso construir também esse tipo de coisa. Outras coisas vão surgindo quando se está pesquisando. Eu posso construir uma teoria a partir da minha prática. (CG, d.c.)

A partir daquele momento, tornou-se uma prática do grupo a investigação, em suas salas de aula, de atividades que realizávamos no grupo ou que eram descritas nos textos teóricos. Dessa forma, cada vez mais as participantes pas- 
GRANDO, R. C.; NACARATO, A. M. Educadoras da infância pesquisando e refletindo sobre a própria prática em matemática

saram a compartilhar suas idéias e experiências. Outro fator que motivou essa dinâmica foi a elaboração do trabalho final, em que a maioria das participantes optou pela realização de atividades com jogos e brincadeiras.

Acreditamos que nesses momentos o professor passa a assumir uma postura de investigação, no sentido apontado por Cochran-Smith e Lytle (1999), que envolve o gerar conhecimento local, teorizar a prática, interpretar e interrogar a teoria e a investigação dos outros, em uma atitude permanente de questionamento. Como pudemos destacar na fala de CG:

Eu gosto de fazer esse tipo de coisa, pôr a criança em questionamento. Já gostava, mas a gente não tem tantos elementos na hora da ação, não flui tão facilmente. Com o curso, com as coisas que a gente está lendo, com tudo, na hora que acontece a ação, a gente passa a enxergar mais. (CG, d.c.)

$\mathrm{Na}$ avaliação final, a maioria das professoras manifestou como a "nova abordagem" vivenciada com jogos e brincadeiras possibilitou ao professor:

a) uma mudança de concepção quanto ao próprio conteúdo matemático:

Foi-nos foi permitido conceber a matemática na Educação Infantil com um novo olhar em que o jogo e as brincadeiras, principalmente, passaram a ser ferramentas importantes de trabalho e não apenas uma opção de lazer e entretenimento. (RA, a.f.) 
b) um redimensionamento da sua própria prática:

Outro aspecto que se destacou foi a troca de experiências e as diferentes possibilidades de trabalhar a alfabetização matemática com os alunos. Percebi o quanto ficamos presas ao contar e registrar quantidades (nem sempre significativas para as crianças) e o quanto podemos trabalhar com o pensamento probabilístico, as diferentes linguagens (gráficos, tabelas...), os registros, as situações-problema. Penso que os encontros quinzenais oportunizaram momentos de revisão e replanejamento da prática e possibilitaram a realização de trabalhos com os alunos para posterior discussão nos encontros seguintes. (DF, a.f.)

Dessa forma, observamos que, ao eleger o jogo e a brincadeira como um foco do trabalho, estabelecemos um forte vínculo com as atividades desenvolvidas na prática profissional docente, permitindo que esta pudesse tornar-se objeto de reflexão, com maior envolvimento por parte do professor, num movimento dialético entre teoria e prática.

\section{A apropriação e (re)significação, pelas professoras, da dinâmica de "dar a voz"}

Uma das dinâmicas que temos adotado em nossa atuação na formação de professores - tanto inicial quanto continuada - tem sido a de "dar voz" ao professor, ou seja, manter uma relação dialógica com ele. Partimos do princípio, defendido principalmente por Freire (1996, p. 135), de que "ensinar exige disponibilidade para o diálogo". O diálogo que se estabelece entre formador e professor é fundamental para que este também passe a incorporar essa prática com seus alunos em sala de aula. 
GRANDO, R. C.; NACARATO, A. M. Educadoras da infância pesquisando e refletindo sobre a própria prática em matemática

Mas dar a voz significa também saber escutar. Partilhamos das idéias de Freire (1996, p. 113) de que:

Se, na verdade, o sonho que nos anima é democrático e solidário, não é falando aos outros, de cima para baixo, sobretudo, como se fôssemos os portadores da verdade a ser transmitida aos demais, que aprendemos a escutar, mas é escutando que aprendemos a falar com eles. Somente quem escuta paciente e criticamente o outro fala com ele, mesmo que, em certas condições, precise falar a ele.

A relação dialógica que se estabelece em contextos de formação representa também uma ação política no sentido de conceber o professor como um produtor de saberes, que tem experiências ricas e valiosas a serem compartilhadas com os seus colegas. Os professores, por sua vez, são excelentes contadores de "casos", gostam de falar sobre suas práticas, contar sobre suas experiências - bem-sucedidas ou não - e expor suas dúvidas e angústias.

Arroyo (2000, p. 236) nos instiga, com suas indagações sobre as trocas entre os professores: "O que levam para trocar? Os mesmos produtos que se encontram em tantos bazares e feiras? Índices de reprovação, evasão? Fracassos-insucesso? O que mais trocam os mestres?”, pergunta ele. O próprio autor afirma que

os mestres no seu cotidiano cultivam, plantam, cuidam, fazem a colheita de seu cultivo, de sua cultura. Na organização seriada, gradeada, nos restritos espaços da turma, da disciplina de cada quintal não há como trocar essas colheitas. Os mestres sentem necessidade de feiras, de espaços de trocas (ARroyo, 2000, p. 236).

Entendemos que os contextos de formação se devam constituir nesses espaços de trocas. Mas o que trocam os professores? Experiências.

Nesse sentido, acreditamos que valorizar a experiência do professor passou a fazer parte das pesquisas e estudos sobre formação de professores. 
Partilhamos das concepções de Larrosa (2002, p. 21) sobre a experiência: "A experiência é o que nos passa, o que nos acontece, o que nos toca. Não o que passa, não o que acontece, ou o que toca". A experiência é formadora, é transformadora. É "um encontro ou uma relação com algo que se experimenta, que se prova" (p. 25). Para o autor, o sujeito da experiência "tem algo desse ser fascinante que se expõe atravessando um espaço indeterminado e perigoso, pondo-se à prova e buscando nele sua oportunidade, sua ocasião" (p. 25).

Nesse sentido, partilhamos das concepções de formação de Jaramillo (2003, p. 95), que, também se apoiando em Larrosa, considera que

A formação pode ser entendida como a arte de fazer com que cada um chegue até si mesmo, até sua própria altura, até o melhor das suas possibilidades [...] O papel do formador não é outro que o de incitador e motivador dessa viagem do formando para o exterior de si. $\mathrm{O}$ formador incita ou instiga o formando a iniciar sua própria viagem (singular e individual), a descobrir seus próprios caminhos.

Embora a experiência seja individual e intransferível, os professores se sentem motivados a compartilhar suas experiências individuais, e as discussões e reflexões que os relatos destas propiciam geram novas aprendizagens, produzem novos saberes. No caso deste grupo, havia um contexto facilitador desses momentos de compartilhamento de experiências: todas as educadoras, por pertencerem a um mesmo sistema de ensino, no mesmo município, eram submetidas a uma mesma orientação pedagógica e curricular.

Muitos foram os momentos nos quais as professoras tiveram a oportunidade de se expor, de contar suas experiências em sala de aula. O depoimento reforça nossa percepção:

O grupo de professoras participantes, no qual pude compartilhar experiências, conquistar e fortalecer amizades, foi outro ponto forte do projeto, pois, dentro da individualidade de cada um, só fez crescer e melhorar todo o processo. (CR, a.f.) 
GRANDO, R. C.; NACARATO, A. M. Educadoras da infância pesquisando e refletindo sobre a própria prática em matemática

Para as alunas da graduação, esses momentos também foram significativos:

Fazer este curso com as professoras da rede foi muito valioso, pois elas têm muitas experiências para compartilhar conosco. Elas contribuíram com suas sugestões e experiências, enriquecendo o curso. E isto só foi possível pela oportunidade que lhes foi concedida pelas coordenadoras do curso, que abriram espaço para a socialização e reflexão. (JA, a.f.)

Outros momentos privilegiados de se "dar voz" e "escutar" as professoras ocorriam quando socializavam com o grupo as estratégias utilizadas para realização das atividades práticas, para os momentos de sistematização dos conceitos trabalhados no encontro.

Acreditamos que a vivência dessa dinâmica, no grupo, possibilitou que as educadoras a utilizassem em sala de aula com seus alunos. A cada encontro, era maior o número de relatos de professoras que, espontaneamente, expunham ao grupo suas práticas de "dar voz e escutar" os alunos. Isso também se evidenciou nos trabalhos de investigação sobre a própria prática. Em todos eles, no momento de registro e reflexão sobre a atividade, essa dinâmica se evidenciou. Destacamos alguns desses registros:

- Para relatar os questionamentos feitos às crianças: uma professora relata a intervenção feita com os alunos:

Duas crianças da torcida se ofereceram para marcar os pontos no placar, e cada uma optou por uma marcação diferente: uma queria marcar com bolinhas e outra com pauzinhos. Perguntamos se poderia ser daquele jeito, se seria adequado. Uma das crianças respondeu que sim, porque era a mesma coisa. Então a professora comentou que não achava que bolinha e pauzinho fossem a mesma coisa. A criança explicou que as figuras não são iguais, mas que mesmo assim valiam o mesmo tanto: uma bolinha valia um ponto e um pauzinho também. (CR, t.i.) 
- Para relatar como tinham realizado os momentos de socialização dos registros: eis como umas das professoras descreve em seu trabalho como foi esse processo com a sua turma:

Quando todos terminaram seus registros, sentamo-nos em círculo e cada um foi explicando seu desenho para os demais colegas. Essa etapa foi muito interessante, pois os colegas iam cobrando dos outros marcas que eles achavam que estavam faltando nos desenhos, e estes se justificavam por terem ou não colocado determinado desenho. (MI, t.i.)

- Para relatar os processos de produção de textos com as crianças: a professora $\mathrm{DF}$, em sua atividade de sala de aula, criou um contexto no qual as crianças deveriam contar a uma outra professora como era a brincadeira do "nunca três", que eles haviam realizado.

Agora eu preciso da ajuda de vocês para explicar da maneira mais clara possível como se faz para brincar. Vocês vão falando e eu vou escrevendo. (DF, t.i.)

No início do semestre, conforme mencionamos no início deste texto, havíamos acordado com as professoras que a realização de uma atividade em sala de aula era parte de nosso planejamento e se constituiria em horas de curso. Não esperávamos, no entanto, que elas se apropriassem das dinâmicas que realizávamos com elas em nossos encontros.

Chamou-nos a atenção que um grupo - embora pertencendo a uma mesma rede de ensino - com pouca prática de um trabalho coletivo, em tão pouco tempo, tenha revelado segurança para expor, em um ambiente colaborativo, suas práticas. Havia um desejo, por parte de algumas professoras, de aplicar, analisar e discutir as atividades desenvolvidas em sala de aula, no grupo coletivo: 
GRANDO, R. C.; NACARATO, A. M. Educadoras da infância pesquisando e refletindo sobre a própria prática em matemática

Eu cresci muito e enriqueci minhas aulas, pois o que eu descobria de novidade tentava aplicar rapidamente na classe e o resultado foi muito bom. Tanto que gostei, que transmiti "prazer" para as crianças, pois eles me cobravam direto sobre os jogos, as comparações e questionamentos. Fiquei muito encantada quando analisei os registros [das crianças] e conversava com eles pedindo para me explicarem. Essa troca que houve, esse questionamento foi riquíssimo. (VC, a.f.)

Entendemos, assim, que as dinâmicas por nós implementadas nos encontros - aprendidas em nossas experiências com formação de professores - possibilitaram que as educadoras se apropriassem delas e as (re)significassem para as suas práticas. Nesse sentido, instigamos essas educadoras para a viagem à qual se referem Larrosa e Jaramillo:

a viagem da qual cada indivíduo volta formado, transformado e conformado, com uma apropriação consciente das coisas que se manifestam em seu caráter, em seu modo de ser e em sua forma de interpretar o mundo (em sua ética e em sua estética) (JARAMILLO, 2003, p. 95).

\section{Considerações finais}

As questões aqui analisadas nos aproximam das discussões realizadas por Cochran-Smith e Lytle (1999) sobre a aprendizagem do professor, quando esta é gerada pelos conhecimentos na prática e da prática. Nesta última dimensão, é fundamental que os professores se envolvam em comunidades de investigação. Acreditamos que conseguimos despertar, em muitas das professoras envolvidas, uma postura de investigação. Principalmente no trabalho final, muitas conseguiram sistematizar suas pesquisas individuais.

Este estudo reforça a importância de contextos de formação que privilegiam os saberes dos professores e toma suas práticas como objeto de estudo e reflexão, na perspectiva, defendida por Arroyo (2000), de constituição da identidade profissional. 
A forma como as educadoras se apropriaram e (re)significaram algumas questões relativas à Educação Infantil - como o jogo, a brincadeira, o papel do registro, a importância de dar voz e escutar o aluno, de negociar regras, de trabalhar coletivamente - contribuiu, sem dúvida, para mudanças de concepção sobre o próprio currículo de matemática para essa faixa etária.

Este estudo aponta também que algumas dinâmicas são mais propícias do que outras para promover mudanças de concepções e de práticas. O professor sente prazer em ler e registrar suas idéias, desde que estas façam sentido para o seu fazer pedagógico. O professor sente prazer em compartilhar suas experiências. Ele precisa sentir-se amparado para dividir suas dúvidas e angústias. O grande desafio posto aos formadores de professores está na busca da melhor forma de equacionar todas essas dinâmicas.

$\mathrm{O}$ grupo revelou-se fundamental para a criação de um ambiente de respeito, confiança, afetividade e, principalmente, segurança. No decorrer do semestre, algumas participantes desistiram - por razões diversas -, mas aquelas que permaneceram assumiram o compromisso de continuidade.

\section{REFERÊNCIAS}

ARROYO, Miguel G. Oficio de mestre: imagens e auto-imagens. 6. ed. Petrópolis: Vozes, 2000.

COCHRAN-SMITH, Marilyn; LYTLE, Susan L. Relationships of knowledge and practice: teacher learning in communities. Review of Research in Education, USA, n. 24, p. 249-305, 1999.

FIORENTINI, Dario; NACARATO, Adair M.; PINTO, Renata A. Saberes da experiência docente em matemática e educação continuada. Quadrante: Revista Teórica e de Investigação, Lisboa, v. 8, p. 33-59, 1999.

FREIRE, João Batista. Educação de corpo inteiro: teoria e prática da educação física. São Paulo: Scipione, 1997. 224 p.

FREIRE, Paulo. Pedagogia da autonomia: saberes necessários à prática educativa. 28. ed. São Paulo: Paz e Terra, 1996.

JARAMILLO, Diana. Processos metacognitivos na (re)constituição do ideário pedagógico 
GRANDO, R. C.; NACARATO, A. M. Educadoras da infância pesquisando e refletindo sobre a própria prática em matemática

de licenciandos em matemática. In: FIORENTINI, Dario (Org.). Formação de professores de matemática: explorando novos caminhos com outros olhares. Campinas: Mercado de Letras, 2003. p. 87-120.

LARROSA, Jorge. Literatura, experiência e formação. In: COSTA, Marisa V. Caminhos investigativos: novos olhares na pesquisa em educação. 2. ed. Rio de Janeiro: DP\&A, 1996. p. 133-160.

LARROSA, Jorge. Notas sobre a experiência e o saber da experiência. Revista Brasileira de Educação, Rio de Janeiro, n. 19, p. 20-28, jan./abr. 2002.

NACARATO, Adair M. Educação continuada sob a perspectiva da pesquisa-ação: currículo em ação de um grupo de professoras ao aprender ensinando geometria. 323 p. Tese (Doutorado em Educação Matemática) - Faculdade de Educação, Unicamp, Campinas, 2000.

PIMENTA, Selma F. Professor reflexivo: construindo uma crítica. In: PIMENTA, Selma F.; GHEDIN, Evandro. Professor reflexivo no Brasil: gênese e crítica de um conceito. 2. ed. São Paulo: Cortez, 2002. p. 17-52.

PIRES, Célia Carolino. Currículos de matemática: da organização linear à idéia de rede. São Paulo: FTD, 2000. 223 p.

PONTE, João Pedro. Investigar a nossa própria prática. In: GTI - Grupo de Trabalho sobre Investigação. Reflectir e investigar sobre a prática profissional. Lisboa: Associação de Professores de Matemática (APM), 2002. p. 5-28.

SMOLE, Kátia Stocco; DINIZ, Maria Ignez; CÂNDIDO, Patrícia. Brincadeiras infantis nas aulas de matemática. Porto Alegre: Artes Médicas, 2000. 84 p.

Texto recebido em 15 out. 2006

Texto aprovado em 29 abr. 2007 